\title{
Farklı Cins Hayvan ile Otlatılan Meraların Sağlık ve Ekolojik Alan Sınıflaması
}

\author{
*Şule ERKOVAN ${ }^{1} \quad$ M. Kerim GÜLLAP ${ }^{1} \quad$ H. İbrahim ERKOVAN ${ }^{1} \quad$ Ali KOÇ² \\ ${ }^{1}$ Atatürk Üniversitesi, Ziraat Fakültesi, Tarla Bitkileri Bölümü, Erzurum \\ ${ }^{2}$ Eskişehir Osmangazi Üniversitesi, Ziraat Fakültesi, Tarla Bitkileri Bölümü, Eskişehir \\ *Sorumlu yazar e-posta (Corresponding author e-mail): erkovan@atauni.edu.tr
}

\begin{abstract}
Öz
Meralar ekolojik faktörlerin yönlendirmesine bağlı olarak kendisini yenileyebildiği gibi geriye gidiş de sergileyebilir. Kullanım özelliklerine bağlı olarak olumlu, olumsuz veya mevcudu muhafaza eden şeklinde davranış sergilemektedir. Bu çalışma sığır, koyun ve sığır ile koyunun birlikte otlatılığı meraların sağık ve ekolojik alan sınıflamasını belirlemek amacıyla Erzurum ili Kargapazarı dağlarında yürütülmüştür. Bitki örtüsü, toprak ve su özellikleri yönünden incelenen mera kesimlerinde önemli farklılıklar gözlemlenmiştir. Sonuçlar bir bütün olarak değerlendirildiğinde, kısa boylu buğdaygillerin hakim olduğu yüksek rakımlı bozkır meralarında kontrolsüz koyun otlatmanın kontrolsüz sığır otlatmaya göre bitki örtüsü ve ilişkili kaynakları daha fazla tahrip edici olduğunu ifade etmemiz mümkündür. Ancak koyunların geniş yapraklı türleri baskı alıına aldığı göz ardı edilmemelidir. Sonuç olarak bozkır meralarının sürdürülebilir kullanımı açııından otlatma mevsimi ve kapasitesine uymak şartıyla sığır ve koyun sürülerinin karışık otlatılmasında fayda vardır.
\end{abstract}

Anahtar Kelimeler: Ekolojik alan, bitki örtüsü, toprak, su

\section{Rangeland Health and Ecological Site Classification of the Rangeland with Grazed Different Type Animals}

\begin{abstract}
Rangelands can renew itself or go backwards depending on the ecological factors. Rangelands exhibit positive, negative or neutral depending on using properties. The objective of this study was to determine rangeland health and ecological site distribution of grazed rangeland with cattle, sheep and mixed stocking in the Kargapazari Mountain Erzurum province. In the investigated rangelands, vegetation, soil and hydrology properties differed significantly. As a result of this study, it is possible to state that uncontrolled grazing with sheep gives more damage to vegetation and related resources than uncontrolled grazing with cattle in highland steppe rangelands where short grasses are dominated. But forbs of sheep taken under pressure should not be ignored. In conclusion, for sustainable use of steppe rangeland, providing suitable grazing season and grazing capacity, sheep and cattle herds can graze as mixture.
\end{abstract}

Keywords: Ecological site, vegetation, soil, hydrology

\section{Giriş}

$\mathrm{M}$ era vejetasyonları canlı ve dinamik bir yapıya sahip olup, otlatma, yakma, toprak, iklim, topoğrafya vb. gibi çeşitli faktörler ile güçlü bir ilişkiye sahiptir. Çevresel faktörler, iklim, toprak ve insan aktiviteleri bitki örtüsünün oluşmasında ve şekillenmesinde önemli olmasına karşın, otlatma bitki örtüsünün değişiminde önemli bir role sahiptir (Arevalo et al. 2011). Bitki tür kompozisyonu üzerine otlayan hayvanların potansiyel etkisi hayvanların cüssesi ve otlama alışkanlıklarına bağlı olarak değişmektedir (Yunusbaev et al. 2003; Altın ve ark. 2011). Büyük baş ile küçükbaş hayvanlar karşılaştırıldıklarında, büyük baş hayvanlar hem daha fazla ot ve tohum tüketmekte hem de tüketmiş oldukları tohumlar sindirim sistemlerinden daha uzun sürede geçtiği için tohumları daha uzak alanlara taşınmaktadırlar (Bakker and OIff 2003). Büyük baş hayvanların bıraktığı dışkılar bünyesinde bulundurduğu tohumların yayılmasını sağlarken, mevcut bitki örtüsünün yapısının 

Type Animals"

değişmesinde de etkili olmaktadırlar (Haskell et al. 2002). Koyun ile otlatma at ile otlatmaya göre bitki örtüsüne daha fazla zarar vermektedir (Rabotnov 1992). Koyunlar sığırlara göre daha seçici otlamakta, genellikle baklagilleri ve yüksek kaliteli diğer familyalara dahil türleri tercih etmektedir (Rose et al. 2012). Hayvanların seçici otlama davranışları türler arasındaki rekabeti etkilemekte, istilacı türler artmakta ve bitki tür kompozisyonunda değişiklikler ortaya çıkmaktadır. Otlatma sadece bitki tür kompozisyonunu etkilememek ile kalmamakta buna ilave olarak sahanın toprak ve hidrolojik özelliklerini de etkilemektedir. Otlayan hayvanların toprak özelliklerine gezinme ve dışkı gibi doğrudan etkilerinin yanı sıra vejetasyonun yapısını ve fonksiyonunu değiştirme gibi dolaylı etkileri bulunmaktadır (Greenwood and McKenzie 2001). Özellikle toprağın nemli olduğu dönemlerde otlatma toprak sıkışmasına neden olmakta, toprakların su geçirgenliğini ve havalanmasını azaltmaktadır (Altın ve ark. 2011). Bitki tür kompozisyonunda olduğu gibi hayvan türlerinin etkisi de farklı olmaktadır. Genellikle hayvan cüssesi arttıkça gezinme esnasında toprağa uyguladığı basınç artmaktadır. Dolayısıyla büyük baş hayvanlar toprağa uyguladıkları basınç (98-192 kPa), küçükbaş hayvanların uyguladığı basınca (48-83 kPa) göre oldukça fazladır ve bu durum büyükbaş hayvanlar ile otlatılan meralarda toprak sıkışması riskini artırmaktadır. Ancak küçükbaş hayvanlar daha fazla hareket ettiği için gezindikleri alanda daha fazla toprak agregatlarının parçalanmasına neden olmaktadırlar (Golodets and Boeken 2006; Li et al. 2008). Bunun bir sonucu olarak küçükbaş hayvanlar toprak yüzeyini daha fazla tahrip etmekte ve toprak yüzeyinde çıplak alanlar veya patikaların oluşmasında etkili olmaktadırlar (Milton et al. 1997). Mera vejetasyon dinamiklerini doğru anlamak ve sürdürülebilir kullanımlarını sağlamak için vejetasyon, toprak, jeoloji, iklim ve fonksiyonel bitki türlerinin potansiyellerinin bilinmesi gerekmektedir. Bu özelliklerin bilinmesi mera dinamiklerinin nasıl değiştiğini, yönetimini, ıslahını, bozulma riskini değerlendirmede daha hızlı karar verilmesine yardımcı olacaktır (Bestelmeyer et al. 2010). Homojen bir yapı göstermeyen meralarda doğru değerlendirmelerin yapılabilmesi için bitki örtüsü, toprak ve su (hidrolojik) özellikleri ile sağlık sınıflamasının bir başka ifade ile ekolojik alan sınıflamasının yapılması gerekmektedir. Bu çalışma sığır, koyun ve sığır+koyunun birlikte otlatıldığı meraların sağlık sınıfı ve ekolojik alan sınıfına etkilerinin ortaya konulması amacıyla yürütülmüştür.

\section{Materyal ve Yöntem}

Araştırma Erzurum ili Kargapazarı Dağlarında 15.83 km² mera alanında 2014 yılında yürütülmüştür. Araştırma sahasının uzun yıllar ortalaması yıllık yağışı $391 \mathrm{~mm}$ ve ortalama sıcaklığı $\quad 5^{\circ} \mathrm{C}$ civarındadır. Araştırmanın yürütüldüğü yılda ise ortalama yağış ve sıcaklık sırasıyla $420 \mathrm{~mm}$ ve $5^{\circ} \mathrm{C}$ olarak kaydedilmiştir. Örneklemelerin yapıldığı mera alanında rakım 2300-2900 m arasında değişmekte olup (Şekil 1) sığır, koyun ve sığır+koyun otlatıldığı birbirlerine komşu mera alanında 5 tekerrürlü olarak örnekleme yapılmıştır. Düşük rakımlar vadilere yakın ve eğimi \%30'dan az, yüksek rakımlar ise dağın yüksek kesimlerinde eğim \%30'un üzerinde yer

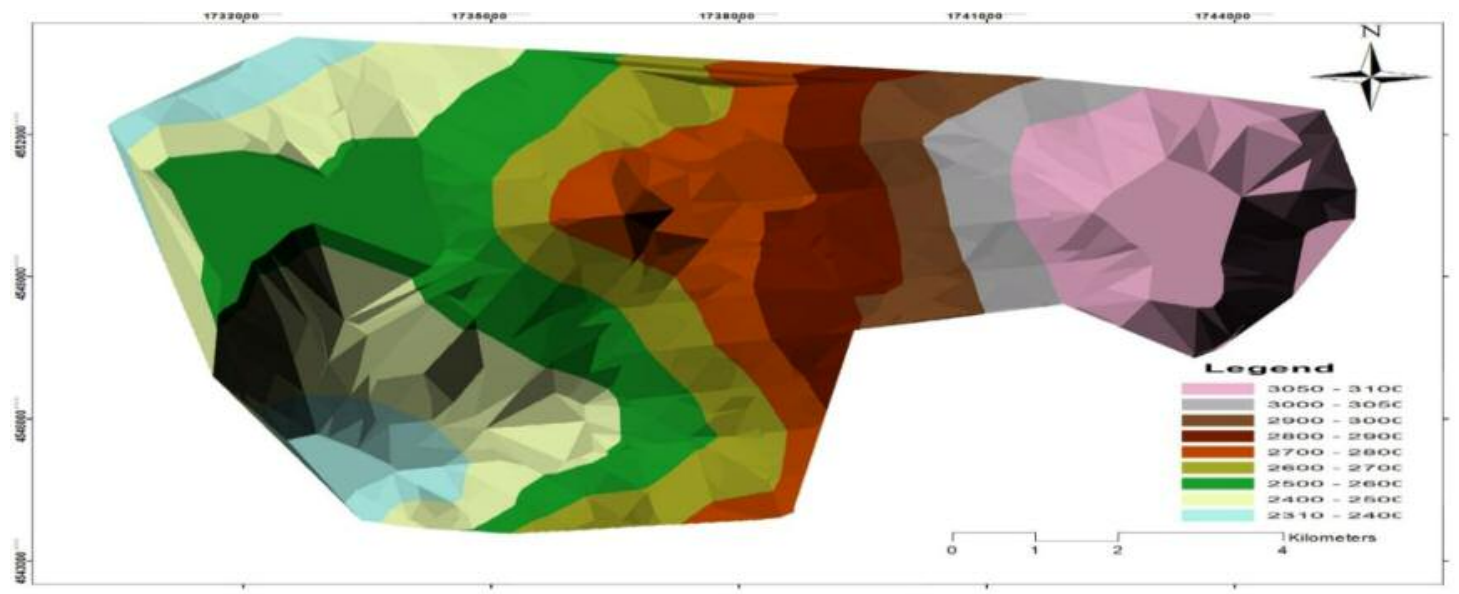

Şekil 1. Örneklemenin yapıldığı meranın rakım değerlerindeki değişim

Figure 1. Changes in altitude values of sampling rangeland 
almaktadır. Seçilen üç mera alanınının özelliklerini şu şekilde sıralamak mümkündür: a) mülkiyeti ve kullanımı şahsa ait sığır otlatırak değerlendirilen mera, b) mülkiyeti devlete ait olup göçerlere kiralanan ve koyun otlatılan mera c) mülkiyeti devlete kullanımı köylüye ait sığır+koyun otlatılarak değerlendirilen meral şeklindedir. Araştırma sahasının toprakları $\% 15.33$ kil, \%30.65 silt ve \%50.02 kum içermekte olup tekstür sınıfı kumlu-tın özelliktedir. Toprakların organik madde içeriği $\% 2.83$, toprak pH'sı 5.74, fosfor içeriği 13.63 $\mathrm{kg} / \mathrm{da}$ ve kireç içeriği \%0.04 olarak tespit edilmiştir. Araştırma sahası topraklarının agregat stabilitesi, dispersiyon oranı, hidrolik iletkenlik ve elektriksel iletkenlik değerleri sırasıyla \%84.20, \%34.38, $2.28 \mathrm{~cm} /$ saat ve 0.22 mmhos/cm'dir. Sığır otlatılan mera kesiminde buğdaygiller familyasına dahil türlerden Festuca ovina, Stipa spp., Agropyron intermedium ve Koeleria cristata, baklagiller familyasına dahil türlerden Medicago spp. ve Onobrychis spp. diğer familyalara dahil türlerden ise Poterium sanguisorba minör, Plantago spp. ve Carex spp. yaygın türlerdir. Koyun otlatılan mera kesiminde sert yapılı olması nedeniyle koyunlar tarafından tercih edilmeyen Alopecurus aucheri baskın tür olmakla birlikte Stipa spp., Eryngium campestre ve Carex spp. yaygın türlerdir. Koyun otlatılan mera kesiminde baklagiller ve diğer familyalara dahil bitki türleri çok yaygın değildir. Sığır ve koyunun karışık otladığı mera kesimlerinde Festuca ovina, Stipa spp., Agropyron intermedium, Koeleria cristata, Alopecurus aucheri, Medicago spp., Onobrychis spp., Astragalus microcephalus, Poterium sanguisorba minör, Eryngium campestre ve Carex spp. yaygın türlerdir.

Ekolojik alan tanımlama ve mera sağlığı sınıflaması Koç ve ark. (2013) tarafından önerilen Türkiye ve benzeri ekolojilerdeki meralar için bitki örtüsü, toprak, ve su durumunu bir arada değerlendiren a) kuru dere sayısı ve genişliği, b) yüzey akış izi, c) patika varlığı, d) çıplak alan, e) mera üzerinde rüzgar veya su ile oyulmuş ve taşınmış toprak varlığı, f) ölü bitki materyal taşınması, g) toprak yüzeyinin erozyona dayanıklılığı, h) toprak bozulması ve kaybı, i) kompozisyon ve tür dağılımının infiltrasyon ve yüzey akışı ile ilişkisi, j) toprak sıkışması, k) fonksiyonel veya yapısal bitki grupları, I) bitki ölümü, $m$ ) ölü materyal, n) üretim, o) istilacı bitkiler, p) çok yıllık bitkilerin yeniden üreme kabiliyetleri ve $r$ ) arzulanan bitkilerde anız yüksekliği olmak üzere toplam 17 mera sağlık indikatörü için gözlem yapılarak not edilmiştir. Mera sağlık sınıfını belirlemede 17 indikatörden $\mathrm{c}, \mathrm{g}, \mathrm{h}, \mathrm{j}, \mathrm{k}, \mathrm{I}, \mathrm{m}, \mathrm{n}, \mathrm{o}, \mathrm{p}$ ve $\mathrm{r}$ bitki örtüsü, a, b, c, d, e, g, h ve j toprak ve a, b, c, d, $e, f, g, h, i, j$ ve $m$ ise hidrolojik özellikler ve sağlık sınıfını belirlenmesinde ele alınmıştır. Fakat ele alınan bu özelliklere göre hazırlanan detay tablolar bildirilerdeki sayfa sınırlaması nedeniyle metin içinde verilmeden sadece özet tablo verilmiştir. Sayılan indikatörlerin durumları tespit edildikten sonra vejetasyon, toprak ve hidrolojik duruma göre değerlendirme yapılarak ekolojik alan sınıflaması yapılmıştır.

\section{Bulgular ve Tartışma}

Sığır ile otlatılan mera kesimlerinde bitki örtüsü, toprak ve su özellikleri sağlık sınıfı yönünden çok iyi sınıfta yer almış ve ele alınan ana özellikler birbiri ile benzerlik sergilemiştir (Çizelge 1). Sığır otlatılan alanda kuru dere çok az, yüzey akış izi yok, patika az, çıplak alan az, taşınmış toprak yok, ölü materyal taşınması yok, erozyon, toprak bozulması ve sıkışması az, fonksiyonel bitki yeterli, bitki ölümü çok az, ölü

Çizelge 1. Farklı cins hayvan ile otlatılan meraların sağlık sınıflaması

Table 1. Health classification of rangelands grazed with different type animals

\begin{tabular}{|c|c|c|c|c|c|}
\hline \multicolumn{6}{|c|}{ Sığır } \\
\hline & Cok zayıf & Zayıf & Orta & İyi & Cok iyi \\
\hline Bitki Örtüsü Özellikleri & & & & & $\mathrm{X}$ \\
\hline Toprak ve Alan Özellikleri & & & & & $\mathrm{X}$ \\
\hline Su (Hidrolojik) Özellikler & & & & & $\mathrm{X}$ \\
\hline \multicolumn{6}{|c|}{ Koyun } \\
\hline & Çok zayıf & Zayıf & Orta & Iyi & Çok iyi \\
\hline Bitki Örtüsü Özellikleri & & $\mathrm{X}$ & & & \\
\hline Toprak ve Alan Özellikleri & & $\mathrm{X}$ & & & \\
\hline Su (Hidrolojik) Özellikler & & & $\mathrm{X}$ & & \\
\hline \multicolumn{6}{|c|}{ Sığır+Koyun } \\
\hline & Çok zayıf & Zayıf & Orta & İyi & Çok iyi \\
\hline Bitki Örtüsü Özellikleri & & & $\mathrm{X}$ & & \\
\hline Toprak ve Alan Özellikleri & & & $\mathrm{X}$ & & \\
\hline Su (Hidrolojik) Özellikler & & & $X$ & & \\
\hline
\end{tabular}


materyal yeterli, üretim çok iyi, istilacı bitki az, bitki türlerinin üremesi ve anız yüksekliği çok iyi durumda olduğu belirlenmiştir. Koyun ile otlatılan mera kesimlerinde bitki örtüsü ve toprak özellikleri bakımından zayıf, su ilişkileri bakımından orta sağlık sınıfında yer almış, bitki örtüsü ve toprak özellikleri büyük oranda benzerlik gösterirken su özellikleri farklılık sergilemiştir (Çizelge 1). Mera kesiminde kuru dere çok, yüzey akış izi, patika, çıplak alan, taşınmış toprak, ölü materyal taşınması, erozyon, toprak bozulması, toprak sıkışması, fonksiyonel bitki türleri, bitki ölümü, ölü materyal, üretim, istilacı bitki, bitki türlerinin üremesi ve anız yüksekliği zayıf veya orta olduğu belirlenmiştir. Sığır ve koyunun birlikte otlatıldığı mera kesimlerinde bitki örtüsü, toprak ve su özellikleri bakımından sağlık sınıfı orta sınıfta yer almış ve toprak, su ve bitki örtüsü özellikleri arasında kısmi benzerlik kaydedilmiştir (Çizelge 1). Sığır ile koyunun karışık otladığı meralarda ise belirlenen 17 indikatör orta, iyi veya çok iyi durumda olduğu tespit edilmiştir. Sı ğır+koyun otlatılan meralarda indikatörler arasındaki farklılık daha yüksek olduğu belirlenmiştir.

Farklı cins hayvan otlatılarak değerlendirilen mera alanlarının sağlık ve ekolojik alan sınıflamaları farklı özellik göstermektedir. Koyun otlatılan mera kesiminde vejetasyon özellikleri indikatörleri genellikle zayıf ve orta sınıfta yer almaktadır. Patika varlığı, toprak yüzeyinin erozyona dayanıklılığı, toprak bozulması, toprak sıkışması, bitki türleri veya grupları, bitki ölümü, ölü materyal, üretim istilacı bitkiler, üreme ve kalan anız miktarı sığır otlatılan kesimde iyi veya çok iyi durumdadır.

Koyunlar sığırlara göre vejetasyon özelliklerini daha çok etkilemektedirler. Sığırlar birim alana daha fazla basınç yapmasına karşılık toprak üzerinde hareketleri az ve yavaştır. Sığırlar koyunlara göre daha az seçici, genellikle uzun boylu buğdaygilleri tercih etmekteler ve kalan anız miktarı yüksektir (Rose et al. 2012). Koyunlar ise çok seçici olup baklagilleri veya lezzetli diğer familyalara dahil türleri tercih ederler ve bitkileri toprak yüzeyine çok yakın koparmaktadırlar. Bir başka ifadeyle kalan anız miktarı çok düşüktür (Rose et al. 2012). Ayrıca koyunlar sığırlara göre daha fazla çiğneme ile bitki örtüsüne zarar vermektedir (Armstrong et al. 1997). Koyunlar çiğneme ile hem canlı bitki örtüsüne zarar verirken hem de anız ve ölü materyalin parçalanmasını hızlandırmaktadır. Bunların bir sonucu olarak vejetasyon yapısında değişikliklerin oluşmasına neden olmaktadır. Nitekim yürüttüğümüz çalışmada yüksek boylu kaba yapılı bir tür olan Alopecurus aucheri koyun otlayan alanda artmış ve istilacı konuma geçmiştir. Bununla birlikte otlatma yoğunluğu kontrol altında meralar için bu değerlendirme daha isabetli olacağına vurgu yapmakta fayda vardır. Özellikle koyun otlatılan mera kesiminde otlatma baskısının çok yüksek olduğuna vurgu yapmak gerekir. Elde edilen sonuçları otlatma yoğunluğunun kontrol altına alınamadığı ve ağır otlatmanın temel sorun olması durumunda koyun sürülerinin mera bitki örtüsü ve bunun tamamlayıcısı olan diğer saha faktörleri açısından daha tahripkar olduğuna şeklinde yorumlamakta fayda vardır. Kuru dere, yüzey akış izi, patika varlığı ve çıplak alan oluşumu ya da varlığı arazinin topografik yapısına bağlı olarak değişmekle birlikte, otlatılan hayvan cinsi oluşumları tetiklemektedir. Koyun gibi küçükbaş hayvanlar toprak kabuğunun canlı kısmını (meralarda verimliliğin en iyi indikatörüdür) (Li et al. 2008) daha fazla tahrip etmekte ve toprağın erozyona karşı direncini azaltmaktadır. Nitekim koyun otlatılan alanlarda çıplak alan oluşumu ve erozyon riski daha yüksek olduğu yapılan araştırmalarda ortaya konmuştur (Milton et al. 1997; Yunusbaev et al. 2003). Taşınmış toprak varlığı, toprak yüzeyinin erozyona dayanıklıı̆̆, toprak bozulması ve kaybı, toprak sıkışması ve infiltrasyon ile yüzey akış ilişkisi otlatılan hayvan cinsine göre zayıf ve çok iyi durum sergilemiştir. Sığır otlatılan alanlarda toprak özelliklerinin koyun ve karışık otlatılan kesimlere göre iyi durumdadır. Sığırlar koyunlara göre toprağa daha fazla basınç uygulamasına karşın daha az gezinmektedirler. Fazla gezinen hayvanlar toprak agregatlarının parçalanmasını teşvik etmektedir. Hayvan hareketleri mera yönetim ilkelerine uygun otlatılan meralarda bir sorun oluşmamakla birlikte bu ilkelerden sapıldığı zaman sorun belirgin olarak ortaya çıkmaktadır (Yunusbaev et al. 2003; Golodets and Boeken, 2006; Li et al. 2008). Ayrıca ağır otlatma bitki örtüsünün toprağı kaplama oranını azaltarak suyun infiltrasyonunu azaltmaktadır. Çünkü toprağı kaplama oranı \%50'nin üzerinde ve anız yüksekliği $2 \mathrm{~cm}$ 'nin üzerinde olduğu zaman infiltrasyonun en yüksek seviyededir (Hamza and Anderson 2005) ve bu değerler azaldıkça infiltrasyon hızı da hızla azalmaktadır. Sığır ile otlatılan alan taşıma kapasitesi hariç genellikle mera yönetim ilkelerine uygun otlatılan bir alandır. Bunun bir sonucu olarak sığır otlatılan 
kesimin özellikleri diğer kesimlere göre daha iyi durumda olması beklenen bir durumdur. Zira bu kesimde çiğnemeye bağıı toprak sıkışmasının yoğun olduğu erken ilkbahar otlatmasının olmadığı gibi, sığır otlaması esnasında bıraktığı anız 3-4 cm civarında olduğu (Altın ve ark. 2011) ve bu yüksekliğin koyun yumağı gibi kısa boylu bitkilerde yeterli anız yüksekliği olduğu dikkate alındığında (Koç ve Gökkuş 1994) sığır otlatılan merada ekolojik alan sınıflarının yüksek olması beklenen bir durumdur.

\section{Sonuç}

Sığır otlatılan mera kesimleri koyun ve karışık otlatmaya göre daha sağlıklı olduğu tespit edilmiştir. Bununla birlikte buradan koyun otlatmasının mera bitki örtüsü ve buna bağlı olarak ekolojik alan değerlerini olumsuz yönde etkilediği şeklinde bir sonuca varmak doğru değildir. Ancak otlatma mevsimi ve kapasitesinin kontrol altına alınamadığı ve kapasitesinin üzerinde otlatmanın yapıldığı meralarda koyun sürülerinin meraların bitki örtüsü ve ekolojik alan değerlerini daha fazla tahrip edici vasıfta olduğunu söylemek mümkündür. Yine sığırların geniş yapraklıları etkili değerlendirememeleri bilinen bir gerçektir ve bu yüzden sığır otlayan meralarda geniş yapraklı bitkiler rekabet avantajı kazanmaktadır. Bu durum mera bitki örtüsünde arzulanmayan yönde gelişmesine sebep olabilir. Bu nedenle bozkır meralarının sürdürülebilir kullanımı açısından otlatma mevsimi ve kapasitesine riayet etmek kaydıyla büyükbaş ve küçükbaş hayvan sürülerinin aynı merada otlatılması isabetli olacaktır.

\section{Kaynaklar}

Altın M., Gökkuş A. ve Koç A., 2011. Çayır ve Mera Yönetimi. T.C. Tarım ve Köyişleri Bakanlığı, Tarımsal Üretim ve Geliştirme Genel Müdürlüğü, Ankara

Arevalo J.R., de Nascimento L., Fernandez-Lugo S., Mata J. and Bermejo L., 2011. Grazing effects on species composition in different vegetation types (La Palma, Canary Islands). Acta Oecologica, 37: 230-238

Armstrong R.H., Grant S.A., Common T.G. and Beattie M.M., 1997. Controlled grazing studies on nardus grasslands: effect of between tussock sward height and species of grazer on diet selection and intake. Grass and Forage Science, 52: 219-231

Bakker E. and OIff H., 2003. Impact of different sized herbivores on recruitment oppurtunites for subordinate herbs in grasslands. Journal of Vegetation Science, 14: 465-474
Bestelmeyer B.T., Moseley K., Shaver P.L., Sanchez H., Briske D.D. and Fernandez-Gimenez M.E., 2010. Practical guidance for developing state-and-transition models. Rangelands, 32: 23-30

Golodets C. and Boeken B., 2006. Moderate sheep grazing in semiarid shrubland alters smallscale soil surface structure and patch properties. Catena, 65: 285-295

Greenwood K.L. and McKenzie B.M., 2001. Grazing effects on soil physical properties and the consequences for pastures. A Review. Australian J. Experimental Agric., 41: 12311250

Hamza M.A. and Anderson W.K., 2005. Soil compaction in cropping systems. a review of the nature, causes and possible solutions. Soil Tillage Research, 82: 121-145

Haskel J.P., Ritchhie M.E. and OIff H., 2002. Fractal geometry predicts varying body size scalling relationships for mammal bird home ranges. Nature, 418: 527-530

Koç A. and Gökkuş A., 1994. Güzelyurt köyü mera vejetasyonunun botanik kompozisyonu ve toprağı kaplama alanı ile bırakılacak en uygun anız yüksekliğinin belirlenmesi. Türk Tarım ve Ormancılık Dergisi, 18: 495-500

Koç A., Erkovan H.I. ve Schacht W.H., 2013. Meralar için ekolojik alan tanımlama ve mera sağlığı sınıflama esasları. Türkiye 10. Tarla Bitkileri Kongresi, 10-13 Eylül 2013, Konya, Bildiriler Kitabı: 598-605

Li C., Hao X., Zhao M., Han G. and Willms W.D., 2008. Influence of historic sheep grazing on vegetation and soil properties of a desert steppe in Inner Mongolia. Agricultural Ecosystem Environment, 128: 109-116

Milton S.J., Dean W.R.J. and Klotz S., 1997. Effects of small-scale animal disturbances on plant assemblages of seta-side land in Central Germany. J. Vegetation Science, 8: 45-54

Rabotnov T.A., 1992. Fitotsenologiya (Phytocenology). Moskow Gos. Univ., Moskow

Rose L., Hertel D. and Leuschner C., 2012. Livestock-type effects on biomass and nitrogen partitioning in temperature pastures with different functional-group abundance. Grass and Forage Science, 68: 386-394

Yunusbaev U.B., Musina L.B. and Suyundukov Y.T., 2003. Dynamics of steppe vegetation under the effect of grazing by different farm animals. Russian J. Ecology, 34: 43-4 